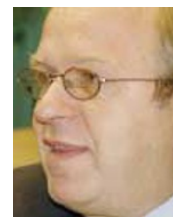

Fast treatment

Europe may halve its approval time for new drugs p364

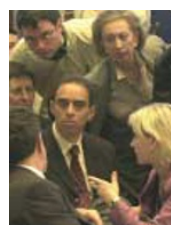

Time for change

Talks wrapped up in

Bonn as Kyoto deal moves forward p365

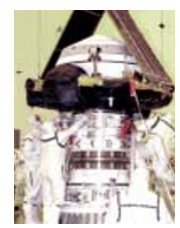

Particle puzzle

NASA hopes to find out how the Solar System was born p366

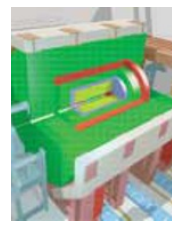

Bang on target

Physicists pledge to develop large linear particle collider p367

\title{
Johns Hopkins researchers fume over government crackdown
}

\section{Meredith Wadman, Washington}

A government-ordered suspension of clinical trials at the largest academic medical centre in the United States has provoked outrage among administrators and investigators.

The shutdown on 19 July at Johns Hopkins University (JHU) in Baltimore was partially revoked after only three days. But its impact will continue for months, as some 2,200 research protocols will be reviewed by ethics boards before they can recommence.

The shutdown followed the death on 2 June of a previously healthy, 24-year-old volunteer in an asthma experiment in which she inhaled hexamethonium, a known lung toxin (see Nature 411, 873; 2001). The university accepted "full responsibility" for her death in a statement accompanying a 16 July report on the incident.

The suspension of research at JHU which the government partially lifted on 22 July after the university submitted an action plan to correct lapses in ethical monitoring brought tensions between US clinical investigators and government regulators to a head.

The university, in a press release, called the action "unwarranted, unnecessary, paralyzing and precipitous", and said that the government had acted "in utter disregard of patients' health and potentially of life”.

"It's almost paradoxical in my mind that an organization whose responsibility is for the safety of patients could by their action put so many patients in my hospital in harm's way," says George Dover, chief paediatrician at the Johns Hopkins Children's Center, part of the university's hospital.

\section{Patient protection}

The US Department of Health and Human Services rejected this criticism, pointing out that the shutdown exempted trials in which it was in the best interests of patients to continue. "We don't want to endanger people's lives. Our goal is to protect people's lives," says Bill Hall, a spokesman.

The shutdown pleased advocates of tougher protection for human subjects. "There is a culture now in academic research that needs to be really shaken," says Vera Hassner Sharav, president of the New York-based
Alliance for Human Research Protection. "A death occurred because of non-compliance," she contends, "and that's not a good enough reason to apply sanctions?"

In recent years, the government has enforced the rules that protect research subjects more strictly, shutting down research at several institutions including the University of California at Los Angeles and Duke University in North Carolina. But JHU, with over $\$ 300$ million in federal funding and more than 137,000 patients enrolled in clinical trials, is its biggest target yet. The suspension also tested the mettle of the government's new Office for Human Research Protections (OHRP), which ordered it. The OHRP was created last year to take over the watchdog role previously performed by a small office inside the National Institutes of Health, the biomedical research agency that funds most of the research. It reports directly to Tommy Thompson, the health secretary.

\section{Minutes missing}

On 22 July, the OHRP announced that it would allow about 500 protocols at JHU to resume immediately. These protocols either involve minimal risk or were adequately documented as having been substantially reviewed in recent minutes of JHU's Institutional Review Boards (IRBs). One of the OHRP's complaints with JHU is that minutes do not exist for 18 of the past 21 IRB meetings, dating back to October 2000.

The remaining 2,200 protocols must be rereviewed by one of JHU's three IRBs, which administrators estimate will take 400 hours of committee time, lasting weeks or months.

Although the university is "pleased" with the formal end to the shutdown, the OHRP has "imposed a whole new set of paperwork requirements that can only impede the resumption of valuable scientific research", says Gary Stephenson, a JHU spokesman.

Even before the suspension was lifted, the university was continuing with hundreds of trials in which it judged that the best interests of patients would be hurt by stopping.

But clinical investigators at JHU were frustrated and angry at what they saw as an overblown reaction to an isolated incident.

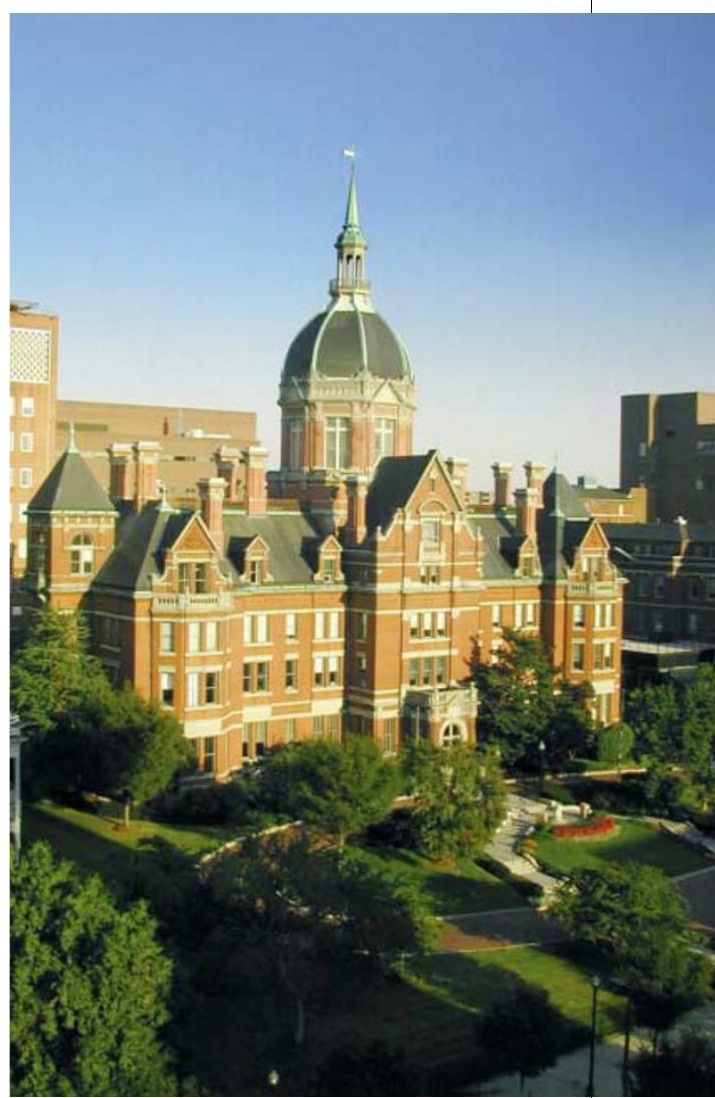

Hospital blanket: the scale of the shutdown has angered clinical researchers at Johns Hopkins.

"It seems unnecessarily harsh and broad to shut down the whole system," says Bruce Bochner, an allergist who has had to halt studies of white blood cells that involve drawing peripheral blood from patients with hay fever and asthma.

Reza Shadmehr, an associate professor of biomedical engineering and neuroscience, analyses motor-control deficits in volunteers with brain diseases, who move robotic arms in his lab. He lost four days of data when his experiments were shut down. But he says that he is more concerned about the long-term impact of the suspension on volunteer trust. "This may impede the ability of at least this scientist to get the trust that he used to have," he says. "I think it's going to take us a few years to rebuild that." 